\title{
Flow Cytometric Measurement of DNA Content in Human Solid Tumors: A Comparison With Cytogenetics
}

\author{
Stefano Rapi, Anna Caldini, Alessandra Fanelli, Piero Berti, Ermanna Lisi, Eugenia Anichini, \\ Raffaella Caligiani, Fiammetta Sbernini, Gianluigi Taddei, Andrea Amorosi, Donata Villari, and \\ Tommaso Susini
}

Clinical Chemistry Unit (S.R., A.C., A.F., P.B.) and Cytogenetics Unit (E.L., E.A., R.C., F.S.), Laboratory Dept., Careggi Hospital, and Institute of Pathological Anatomy (G.T., A.A.), Clinic of Urology (D.V.), and Obstetrics and Gynaccology Dept. (T.S.), University of Florence, Florence, Italy

\begin{abstract}
The aims of this study were: (1) to test the accuracy of flow cytometry (FC) in the measurement of DNA content in human solid tumors, (2) to correlate the FC DNA-index (DI) with the chromosome modal number (CMN) provided by cytogenetic analysis (CG), and (3) to investigate the most frequent pitfalls in FC histograms classification. FC and CG analyses were performed in parallel on 113 samples of human solid tumors of different origin. FC provided an evaluable histogram in 110 out of 113 cases $(97 \%)$, whereas a successful CG culture was obtained in 79 out of 113 samples $(72 \%)$. In the 79 cases evaluable by both FC and CG, a concordant ploidy status was found in 66 cases $(84 \%)$ (47 diploid and 19 aneuploid) $(P<0.001$, chisquare test). In the 19 concordant aneuploid tumors a close correlation between the CMN and the DI was found $(y=0.019 x+0.151 ; r=0.860)$. Concerning the 13 discordant cases, $11(85 \%)$ were classified as aneuploid by FC and as diploid by CG, while 2 cases (15\%) were CG aneuploid (1 near-diploid and 1 tetraploid) and FC diploid. The current study suggests that FC is a reliable method for the measurement of tumor DNA content of the studied solid tumors. Special attention should be paid to the improvement of DNA histograms quality, in order to reduce the difficulties in the detection of near-diploid and near-tetraploid cell populations. Multiple sampling should be warranted whenever possible. (c) 1996 Wiley-Liss, Inc.
\end{abstract}

Key terms: Flow cytometry, cytogenetics, DNA index, cancer

Flow cytometry (FC) is a commonly used technique to estimate DNA content and proliferative activity in a wide variety of human neoplasms $(3,14)$. Cytogenetic analysis (CG) provides accurate information on ploidy status and/or chromosome structural aberrations. Both techniques can detect abnormal DNA pattern and tumor heterogeneity. Several studies support the view that FC aneuploid peaks represent clones of cells with abnormal chromosome number. Most of these investigations have been performed on human acute leukemias $(1,2)$. In fact, CG and FC analyses are more difficult to carry out in solid tumors and, as a consequence, only few patients with such malignancies have been studied by both techniques $(4,7,9,16,18,21,24,26)$. The picture is further confused by differences in the analytical methods used as well as in the type of tumors examined, which may both account for the significant variability in FC and CG concordance reported in the literature. Indeed, CG provides the "gold standard" for ploidy assessment, despite that this procedure is more complex in solid tumors. The correlation of FC and CG in cervical and endometrial carcinomas has never been investigated.

In the current study, we performed in parallel FC and CG analyses in a large series of human cervical, endometrial and renal neoplasms. The aims of the study were as follows: (1) to evaluate the reliability of $\mathrm{FC}$ in identifying cell populations with abnormal DNA content, (2) to correlate the FC DNA index (DI) with the chromosome modal number (CMN) given by CG analysis, and (3) to investigate the most frequent pitfalls in $\mathrm{FC}$ histograms classification.

\section{MATERIALS AND METHODS}

FC and CG analyses were performed on 113 fresh tissue samples from patients affected by tumors of different

Received for publication July 1, 1995; accepted May 1, 1996.

Address reprint requests to Dr. Stefano Rapi, Dipartimento di Laboratorio, U.O. di Chimica Clinica, S. Luca, Azienda Ospedaliera Careggi, Viale Morgagni 85, 50134 Florence, Italy. 
origin. Overall, 86 cases of squamous cell carcinoma of the uterine cervix, 21 cases of renal carcinoma, and 6 cases of endometrial carcinoma were studied. In 6 cases of uterine cervix carcinoma both a preoperative biopsy specimen and a sample obtained from the surgical specimen were analyzed.

Immediately after surgery, a fresh tumor sample was placed into sterile minimal nutrient transport medium supplemented with antibiotics and then it was divided by the same trained pathologist into two specular parts for histological and laboratory examinations. The specimen for laboratory examination was mechanically disaggregated with scissors and the resulting cell suspension was divided into aliquots for FC and CG analyses.

\section{Cytogenetic Analysis}

The cell suspension was submitted to enzymatic digestion by treatment in Hank's solution, containing Type I collagenase (Sigma Chemicals, St. Louis, MO; $1 \mathrm{mg} / \mathrm{ml}$ for endometrial and cervical carcinomas; $2.5 \mathrm{mg} / \mathrm{ml}$ for renal carcinoma). Samples were incubated for $3 \mathrm{~h}$ at room temperature (for $15-20 \mathrm{~min}$ at $37^{\circ} \mathrm{C}$ for renal cancer). The reaction, controlled under light microscope, was stopped by centrifugation $(2,000 \mathrm{~g}$ for $10 \mathrm{~min})$. Pellets were resuspended in RPMI 1640 supplemented with $20 \%$ fetal bovine serum ( $10 \%$ for renal tissue) and $100 \mu \mathrm{g} / \mathrm{ml}$ penicillin, streptomicin, and insulin. Cells were seeded in at least 5 glass slides for each sample, placed in a $60 \mathrm{~mm}$ Petri disk with $4 \mathrm{ml}$ culture medium, and then incubated at $37^{\circ} \mathrm{C}$ in $5 \% \mathrm{CO}_{2}$ atomosphere. After 6 to 15 days culture, slides were blocked with colcemid $(0.2 \mu \mathrm{g} / \mathrm{ml} ; 4 \mathrm{~h}$ and $30 \mathrm{~min}$ at $37^{\circ} \mathrm{C}$ ). Cells were subsequently treated with $0.075 \mathrm{M} \mathrm{KCl}$ at $37^{\circ} \mathrm{C}$ for $8 \mathrm{~min}$ and then fixed with ethanol-glacial acetic acid (3:1). Slides were subjected to chromosome banding according to the quinacrine moustard procedure (5). Control cell cultures of normal homologous tissue or peripheral blood lymphocytes from the same patient have been performed whenever possible.

A culture was considered abnormal when the same numerical chromosome aberration was present in at least 2 metaphases from different colonies. Slides were observed by means of a fluorescence microscope. The kariotype was evaluated by one of us, without knowledge of the FC analysis results.

\section{Flow Cytometry}

After mechanical mincing, cell suspensions were filtered through a $50 \mu \mathrm{m}$ mesh nylon filter in order to remove cell aggregates and then cells were fixed in $70 \%$ cold ethanol. After two washings in phosphate-buffered saline solution ( $150 \mathrm{mmol} / \mathrm{L}, \mathrm{pH} 7.2$ ), cells were treated with RNase $0.5 \mathrm{mg} / \mathrm{ml}$ (Boehringer Mannheim, Indianapolis, IN) for $30 \mathrm{~min}$ at $37^{\circ} \mathrm{C}$ and then stained with Propidium Iodide (PI, Sigma Chemicals, $50 \mu \mathrm{g} / \mathrm{ml}$ in Sodium Citrate $0.1 \%$ ) for $12 \mathrm{~h}$ at $4^{\circ} \mathrm{C}$. When homologous normal tissue was not available, peripheral blood lymphocytes, treated as the tumor sample, were used as external diploid reference standard (19).
Samples were analyzed on a Coulter Epics Elite (Coulter Electronics, Hialeah, FL) flow cytometer equipped with a $488 \mathrm{~nm}, 15 \mathrm{~mW}$ argon ion laser. A minimum of 20,000 cells for the surgical specimens and 10,000 cells for the bioptic samples were collected during FC analysis.

Histograms were obtained after gating on peak red vs. integrated red fluorescence to minimize doublets contribution. The DI of the sample was calculated by dividing the mean channel of the sample G0/G1 peak by the mean channel of the diploid $\mathrm{GO} / \mathrm{G} 1$ peak. The fraction of cells in different phases of cell cycle was determined using the Multicycle 2.53 software program (Phoenix, San Diego, CA).

A specimen was considered as FC diploid when the corresponding histogram showed a single symmetric G0/G1 peak with a coefficient of variation (CV) $<8 \%$ (Fig. 1a) (20). A clone was considered as FC near-diploid when the histogram showed a G0/G1 aneuploid population peak with $0.8<\mathrm{DI}<1.2$ and clearly distinct from the diploid G0/G1 (Fig. 1b). Samples showing a single population with $\mathrm{CV}>8 \%$ and/or peak shoulder were considered not evaluable.

A sample was considered as FC aneuploid if the histogram showed two distinct G0/G1 populations, each comprising at least $5 \%$ of the total sample (Fig. 1c). A clone was defined as FC tetraploid when the peak in diploid $\mathrm{G} 2 / \mathrm{M}$ region $(1.8<\mathrm{DI}<2.2)$ represented at least $10 \%$ of the total cell number and the relative S-phase and G2/M peak were clearly identified (Fig. 1d). Taking into account Joensuu and Kallioniemi observations (11) on the variability in FC histograms classification among different investigators, all histograms in the current study were appropriately modeled by the same operator, without knowledge of the corresponding CG analysis results.

\section{RESULTS}

The flow sheat of results is shown in Figure 2. Three samples (two cervical and one renal carcinoma) did not meet criteria to define ploidy status by FC and failed to grow in culture for CG. Therefore, they have been excluded from the study. Among the 110 cases evaluable by FC, 31 specimens ( $28 \%$ ) failed to grow in culture for CG analysis. Thus, 79 samples ( $72 \%$ ) were evaluable by both techniques. Concerning the different types of tumors, all endometrial samples $(n=6)$ were evaluable by both techniques, whereas in cervical cancer the CG evaluable samples were 62 out of $86(72 \%)$ and in renal carcinoma 13 out of 21 (62\%). Mean CVs of tumor cell peak for diploid and aneuploid samples which did not grow in culture were $6.4 \%$ (range $4.3-8.0 \%$ ) and $5.9 \%$ (range 3.9-8.0\%), respectively. The incidence of FC aneuploid samples was not significantly different in the group of unevaluable CG samples as compared with the evaluable cases, 15 out of 31 vs. 30 out of 79, respectively. Furthermore, no difference in DI distribution between grown and not grown tumors was found in the group of FC aneuploid samples. Overall, no difference in growth capacity was noted according to histotype, grade of differentiation, and stage of the tumor. The results of FC and 

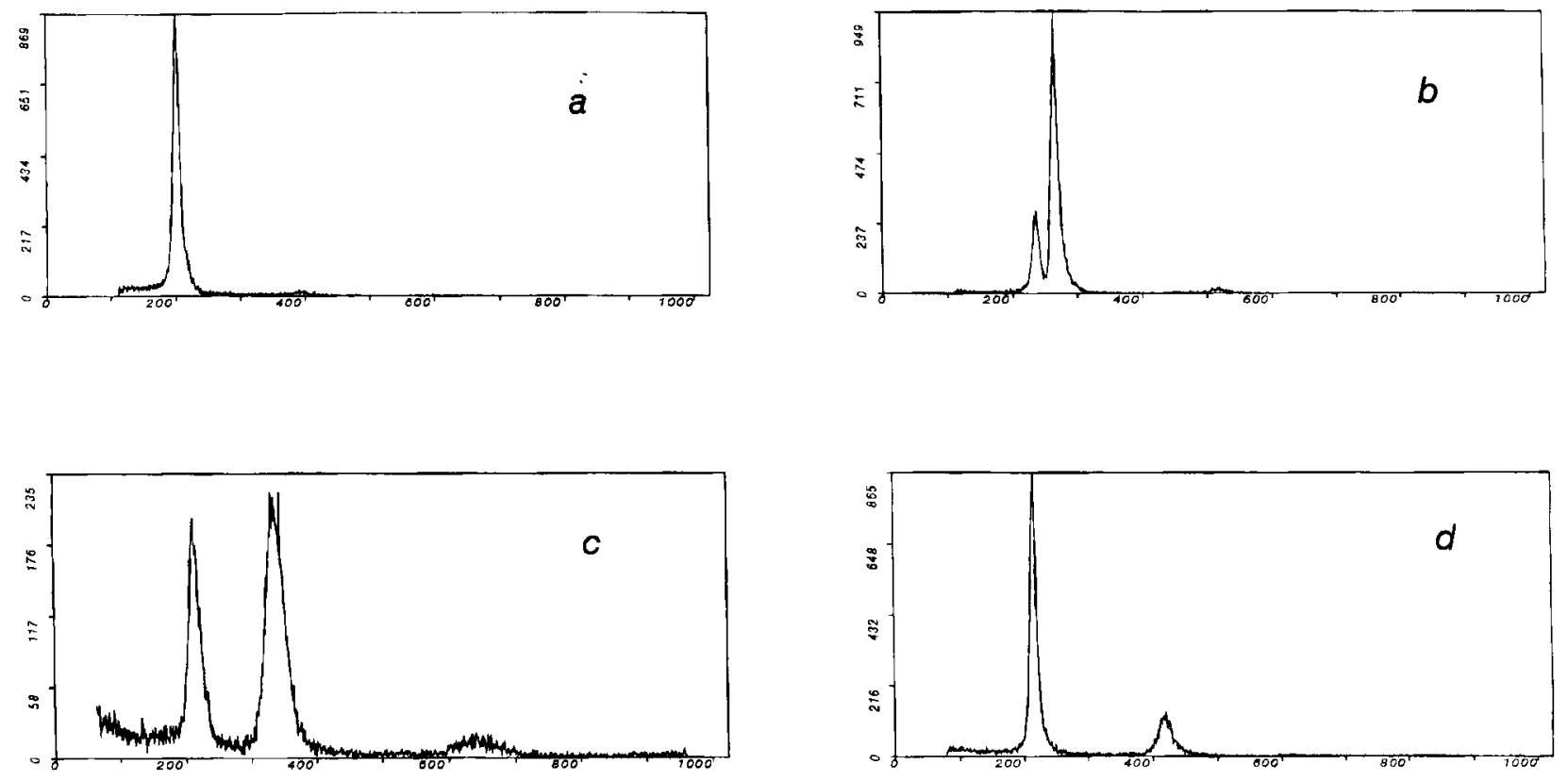

FiG. 1. Flow cytometric histograms showing respectively: (a) a diploid sample; (b) a near diploid sample; (c) an aneuploid sample; (d) a tetraploid sample.

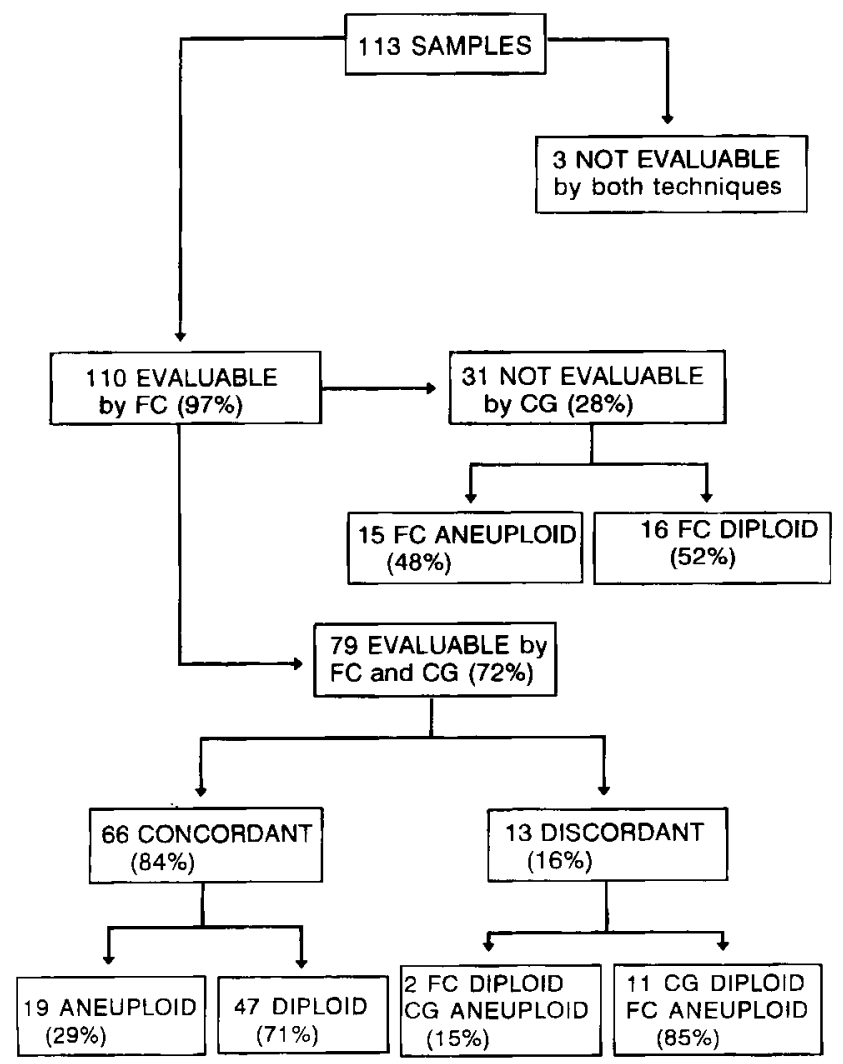

Fig. 2. Flow sheat of results.
Table 1

Concordant Diploid Samples: Number of Colonies and Metaphases and CV of Tumor Cell Peak (Mean value and range $)^{\mathrm{a}}$

\begin{tabular}{lrccc}
\hline $\begin{array}{l}\text { Tumor } \\
\text { type }\end{array}$ & $\mathrm{N}$ & $\begin{array}{c}\text { Number of } \\
\text { colonies } \\
(\overline{\mathrm{x}} \text { (range) }\end{array}$ & $\begin{array}{c}\text { Number of } \\
\text { metaphases } \\
\bar{x} \text { (range) }\end{array}$ & $\begin{array}{c}\% \text { CV tumor } \\
\text { cell peak } \\
\bar{x} \text { (range) }\end{array}$ \\
\hline $\mathrm{ke}$ & 3 & $9(7-11)$ & $20(13-33)$ & $6.1(4.5-7.9)$ \\
$\mathrm{kr}$ & 5 & $6(3-10)$ & $27(11-45)$ & $3.5(2.6-4.4)$ \\
$\mathrm{kc}$ & 39 & $9(2-15)$ & $17(4-57)$ & $7.0(3.8-8.0)$ \\
Total & 47 & $8(2-15)$ & $18(4-57)$ & $6.5(2.6-8.0)$ \\
\hline
\end{tabular}

aTumor type: $\mathrm{kc}=$ cervical carcinoma; $\mathrm{ke}=$ endometrial carcinoma; $\mathrm{kr}=$ renal carcinoma.

CG analyses were concordant in 66 out of 79 samples $(84 \%)(P<0.001$, chi-square test $)$. Forty-seven of them (71\%) were diploid and $19(29 \%)$ were aneuploid. The number of colonies and metaphases obtained in CG cultures, as well as the tumor cell peak CV of FC histograms for diploid concordant samples, are summarized in Table 1. Tumor type, stage, grade of differentiation, and the correspondent results of FC and CG analyses of the 19 concordant aneuploid samples are presented in detail in Table 2. In the 19 concordant aneuploid cases, a close correlation between the CMN and the DI was found ( $y=$ $0.019 \times+0.151 ; r=0.860 ; P<0.001)$. Such correlation is graphically represented in Figure 3. Among the 13 cases in which discrepancies were found, 11 cases ( $85 \%$ ) showed aneuploid populations by FC but were diploid by CG, and 2 cases (15\%) were CG aneuploid and FC diploid. The results of FC and CG analyses of the discordant samples are reported in Table 3 . All of the 6 tumors which 
Table 2

Histopathological Data, CG and FC Results of Concordant Aneuploid Samples

\begin{tabular}{|c|c|c|c|c|c|c|c|c|}
\hline Sample no. & $\begin{array}{c}\text { Tumor } \\
\text { type }^{\mathrm{a}}\end{array}$ & Stage & Grade $^{b}$ & $\begin{array}{l}\text { Chromosome } \\
\text { modal number }\end{array}$ & $\begin{array}{c}\text { Number of } \\
\text { colonies }\end{array}$ & $\begin{array}{c}\text { Number of } \\
\text { methaphases }\end{array}$ & DNA-Index & $\begin{array}{l}\% \text { CV tumor } \\
\text { cell peak }\end{array}$ \\
\hline 1 & kc & $1 \mathrm{~b}$ & 3 & 80 & 3 & 4 & 1.98 & 5.5 \\
\hline 2 & ke & $2 a$ & 1 & 85 & 4 & 6 & 1.99 & 5.0 \\
\hline 3 & $\mathrm{kc}$ & $1 \mathrm{~b}$ & 2 & 80 & 9 & 12 & 1.90 & 5.9 \\
\hline 4 & kc & $2 b$ & nk & 80 & 4 & 7 & 1.86 & 6.2 \\
\hline 5 & kc & lb & 2 & 92 & 7 & 9 & 2.00 & 7.0 \\
\hline 6 & $\mathrm{kc}$ & lb & 2 & 92 & 7 & 11 & 2.10 & 8.0 \\
\hline 7 & $\mathrm{kc}$ & $2 b$ & 3 & 55 & 5 & 9 & 1.20 & 5.1 \\
\hline 8 & ke & 2 & 3 & 48 & 5 & 7 & 1.10 & 6.0 \\
\hline 9 & kc & $2 a$ & 4 & 88 & 7 & 10 & 1.90 & 5.1 \\
\hline 10 & kc & $1 b$ & 2 & 88 & 6 & 9 & 1.60 & 8.0 \\
\hline 11 & $\mathrm{kc}$ & $2 a$ & 2 & 47 & 5 & 7 & 1.30 & 5.0 \\
\hline 12 & kc & $2 a$ & 2 & 75 & 3 & 7 & 1.70 & 6.0 \\
\hline 13 & kc & $1 b$ & 2 & 70 & 4 & 7 & 1.56 & 6.5 \\
\hline 14 & kc & nk & nk & 48 & 7 & 11 & 1.10 & 5.1 \\
\hline 15 & kc & nk & nk & 98 & 8 & 12 & 1.90 & 6.6 \\
\hline 16 & $\mathrm{kr}$ & tl & 2 & 45 & 4 & 20 & 0.72 & 5.9 \\
\hline 17 & $\mathrm{kr}$ & $\mathrm{t} 2$ & 3 & $78,92,156$ & 7 & 36 & 1.20 & 4.8 \\
\hline 18 & $\mathrm{kr}$ & $\mathrm{t} 3$ & 4 & 87 & 4 & 13 & 1.65 & 5.7 \\
\hline 19 & $\mathrm{kr}$ & $\mathrm{t} 2$ & 2 & 72 & 10 & 37 & 1.59 & 4.8 \\
\hline
\end{tabular}

Tumor type: $\mathrm{kc}=$ cervical carcinoma; $\mathrm{ke}=$ endometrial carcinoma; $\mathrm{kr}=$ renal carcinoma.

${ }^{b}$ Grade of differentiation for ke and $k r$; Broder's grade for $\mathrm{kc}_{\mathrm{i}} \mathrm{nk}=$ not known.

had samples obtained both from preoperative biopsy and surgical specimen had concordant results of CG and FC analyses. However, in one case both techniques showed an aneuploid tumor in the biopsy specimen and a diploid one in the surgical sample.

\section{DISCUSSION}

In the current study, the FC measurement of DNA content in human solid tumors has shown a high degree of concordance ( $84 \%$ ) with the results of CG analysis of the same tumor samples. Moreover, in the concordant aneuploid cases a close correlation between the FC DI and the CMN as determined by CG was found (Fig. 3).

The $84 \%$ rate of concordance we found is superior to those reported in the studies which tested the FC accuracy with a similar approach $(6,7,9,16-18,21,22,24-26)$. In fact, Shackney et al. (18) found a concordance of $30 \%$ in a series of 20 human solid tumors from other sites than those investigated by us, and Dressler et al. (7) reported a concordance of $69 \%$ using paraffin embedded tissue for FC analysis. Coon et al. (6) in a retrospective study on paraffin embedded samples of urinary bladder carcinoma had a better concordance rate (87\%). However, despite the elevated agreement between $F C$ and $C G$ analyses results, they failed to find any correlation between the FC DI and the CMN in their aneuploid samples. Hence, tumor heterogeneity, a frequent feature in urinary bladder carcinoma, may account for such an outcome (15). Several factors are known to be involved in determining the accuracy of FC and CG analyses. These factors include the different types of tumor analysed, the fresh tissue sample instead of the paraffin embedded material, as well as differences in the dyes and the staining procedures, or in the software used for the FC histograms evaluation. Variation in any of these factors and, for instance, the large number

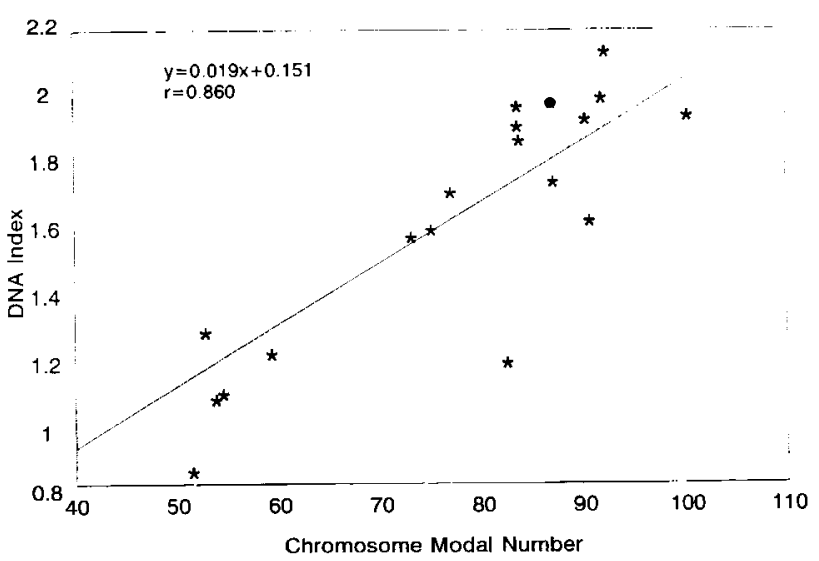

FIG. 3. Correlation between chromosome modal number and DNAindex in concordant aneuploid samples (See Table 2).

of diploid samples among the evaluable concordant cases (47/79) in our study, may have been responsible for the elevated concordance degree we found.

The good correlation between the FC DI and the CMN in the aneuploid cases obtained in the current study, in contrast with the poor correlation reported by Coon et al. (6), might be explained by technical reasons. In fact, in the specimen processing, we first performed a mechanical disaggregation until a cell suspension was obtained and, subsequently, we divided the sample into aliquots for FC and CG analyses. Indeed, this procedure reduced the possibility that tumor heterogeneity may have biased the results in our study. Interestingly, in one of the few cases with poor correlation between DI and CMN (Table 2 , case 17), CG revealed several aneuploid colonies, with a high variable chromosome number. It is also notewor- 
Table 3

Histopathological Data, CG and FC Results of Discordant Samples

\begin{tabular}{|c|c|c|c|c|c|c|c|c|}
\hline Sample no & $\begin{array}{l}\text { Tumor } \\
\text { type }^{a}\end{array}$ & Stage & Grade $^{b}$ & $\begin{array}{l}\text { Chromosome } \\
\text { modal number }\end{array}$ & $\begin{array}{c}\text { Number of } \\
\text { colonies }\end{array}$ & $\begin{array}{l}\text { Number of } \\
\text { methaphases }\end{array}$ & DNA-Index & $\begin{array}{l}\% \text { CV tumor } \\
\text { cell peak }\end{array}$ \\
\hline 1 & kc & $1 b$ & 4 & 46 & 14 & 36 & 1.42 & 8.0 \\
\hline 2 & kc & $1 \mathbf{b}$ & 3 & 46 & 12 & 21 & 1.60 & 6.0 \\
\hline 3 & kc & $1 \mathrm{~b}$ & 3 & 46 & 6 & 19 & 1.30 & 7.0 \\
\hline 4 & kc & $1 b$ & 4 & 46 & 14 & 36 & 1.39 & 4.1 \\
\hline 5 & kc & $1 b$ & 2 & 46 & 5 & 7 & 1.87 & 6.1 \\
\hline 6 & kc & $2 b$ & 1 & 46 & 4 & 6 & 1.15 & 5.5 \\
\hline 7 & kc & $2 a$ & 3 & 46 & 7 & 13 & 1.30 & 7.0 \\
\hline 8 & ke & 1 & 2 & 46 & 10 & 17 & 1.20 & 8.0 \\
\hline 9 & $\mathrm{kr}$ & t3 & 3 & 46 & 4 & 15 & 1.80 & 7.1 \\
\hline 10 & $\mathrm{kr}$ & t4 & 3 & 46 & 3 & 11 & 1.80 & 4.0 \\
\hline 11 & kr & $t 2$ & 1 & 46 & 6 & 24 & 1.08 & 4.3 \\
\hline 12 & kc & $2 a$ & 3 & 88 & 4 & 6 & 1.00 & 8.0 \\
\hline 13 & kr & t1 & 2 & 47 & 6 & 14 & 1.00 & 5.6 \\
\hline
\end{tabular}

aTumor type: $\mathrm{kc}=$ cervical carcinoma; $\mathrm{ke}=$ endometrial carcinoma; $\mathbf{k r}=$ renal carcinoma.

bGrade of differentiation for ke and kr; Broder's grade for kc.

thy that among the 6 cases of cervical cancer which were analysed both prior to and after surgery, one case showed aneuploidy in the preoperative biopsy, whereas it displayed a diploid pattern in the surgical sample. Both samples were concordant concerning the FC and CG analyses results. This outcome points out once again the problem of tumor heterogeneity as one of the prominent sources of misclassification of FC histograms $(4,10,12)$. Therefore, to improve the reliability of FC determinations, multiple sampling should be warranted whenever possible.

In the current study, discrepancies between FC and CG analyses in the detection of aneuploidy were found in 13 cases ( $16 \%$ ). Most of them ( 11 cases) resulted aneuploid by FC, but were diploid by CG. Eight out of 13 (61\%) discordant cases occurred in the near-diploid or in the near-tetraploid region (Table 3 , cases $6,8,11,13$, and cases $5,9,10,12$, respectively). This outcome is in agreement with the available evidence that $\mathrm{FC}$ analysis reliability is considerably reduced in such regions (8).

The remaining discordant samples exhibited FC aneuploidy in the S-region, whereas CG studies showed only normal diploid metaphases (Table 3, cases $1,2,3,4,7$ ). A possible explanation for such discrepancies may be that diploid methaphases were derived from normal cells present in the sample. A slowly growing tumor may have produced a prominent aneuploid G1 peak in the FC DNA histogram, with no aneuploid mitosis available for CG analysis, as previously suggested by others $(7,9,25)$.

$C G$ analysis is a labour-intensive and time-consuming procedure and therefore it is not suitable for routine clinical use. Furthermore, CG is difficult to perform in solid tumors, as it is confirmed by the considerable number of samples which failed to grow in culture (30\%), whereas FC analysis provided an evaluable DNA histogram in all but three of the total samples (97\%). On the other hand, special attention should be paid to the improvement of DNA histogram quality, in order to reduce the difficulties in the detection of near-diploid and near-tetraploid cell populations. The knowledge of tumor DNA content has a relevant clinical value for the clinicians facing endome- trial, cervical, and renal cancer $(3,13,23)$ and other neoplasms as well (3). In conclusion, in the studied neoplasms FC compared to CG appears to be a fast and reliable technique to assess the DNA content in large series of tumor samples.

\section{LITERATURE CITED}

1. Barlogie B, Hittelman W, Spitzer G, Trujillo JM, Hart JS, Smallwood L, Drewinko B: Correlation of DNA distribution abnormalities with cytogenetic findings in human adult leukemia and lymphoma. Cancer Res 37:4400-4407, 1977.

2. Barlogie B, Stass S, Dixon D, Keating M, Cork A, Trujillo JM, McCredie KB, Freireich EJ: DNA aneuploidy in adult acute leukemia. Cancer Genet Cytogenet 28:213-228, 1987.

3. Bauer KD, Duque RE, Shankey TV: Clinical Flow Cytometry. Williams and Wilkins, Baltimore, 1993.

4. Bringuier PP, Bouvier $R$, Berger N, Piaton E, Revillard JP, Perrin $P$, Devonec M: DNA ploidy status and DNA content instability within single tumors in renal cell carcinoma. Cytometry 14:559-564, 1993.

5. Casperson T, Zech $\mathrm{L}$, Johansoon $\mathrm{C}$ : Analysis of the human metaphase chromosome set by aid of DNA binding fluorescent agents. Exp Cell Res 62:490-497, 1990.

6. Coon JS, Schwartz D, Summers JL, Miller III AW, Weinstein RS; Flow cytometric analysis of deparaffinized nuclei in urinary bladder carcinoma. Comparison with cytogenetic analysis. Cancer 57:1594$1601,1986$.

7. Dressler DG, Duncan MH, Varsa EE, McConnell TS: DNA content measurement can be obtained using archival material for DNA flow cytometry. A comparison with cytogenetic analysis in 56 pediatric solid tumors. Cancer 72:2033-2041, 1993.

8. Duque RE, Andreeff M, Braylan RC, Diamond LW, Peiper SC: Consensus review of the clinical utility of DNA flow cytometry in neoplastic hematopathology. Cytometry 14:492-496, 1993.

9. El-Naggar AK, Pathak S: Cytogenetic and corresponding flow cytometric DNA analyses of renal cell neoplasms. Anticancer Res 12 : 1491-1500, 1992.

10. Fernoe M, Baldertorp B, Ewers SB, Idvall I, Olsson $H$, Sigurdsson $H$, Killander D: One or multiple samplings for flow cytometric DNA analysis in breast cancer-prognostic implications? Cytometry 13: 241-249, 1992.

11. Joensuu $H$, Kallioniemi OP: Different opinions on classification of DNA histograms produced from paraffin-embedded tissue. Cytometry 10:711-717, 1989 .

12. Kallioniemi OP: Comparison of fresh and paraffin-embedded tissue as starting material for DNA flow cytometry and evaluation of intratumor heterogeneity. Cytometry 9:164-169, 1988.

13. Leeminen A, Paavonen J, Vesterinen E: Deoxyribonucleic acid flow cytometric analysis of cervical adenocarcinoma: Prognostic significance of deoxyribonucleic acid ploidy and S-phase fraction. Am $\mathbf{J}$ Obstet Gynaecol 162:848-853, 1990. 
14. Melamed MR, Lindmo T, Mendelsohn ML: Flow Cytometry and Sorting, Ed. 2. Wiley-Liss Inc., New York, 1990.

15. Norming U, Nyman CR, Tribukait B: Comparative flow cytometric deoxyribonucleic acid studies on exophytictumor and random mucosal biopsies in untreated carcinoma of the bladder. J Urol 142 1442-1447, 1989.

16. Petersen SE, Friedrich U: A comparison between flow cytometric ploidy investigation and cromosome analysis of 32 human colorectal tumors. Cytometry 7:307-312, 1986

17. Remvikos $Y$, Gerbalt-Seureau $M$, Vielh $P$, Zafrani B, Magdelenat $H$ Dutrillaux B: Relevance of DNA ploidy as a misure of genetic deviation: A comparison of flow cytometry and cytogenetics in 25 cases of human breast cancer. Cytometry 9:612-618, 1988

18. Shackney SE, Burholt DR, Pollice AA, Smith CA, Pugh RP, Hartsock RJ: Discrepancies between flow cytometric and cytogenetic studies in the detection of aneuploidy in human solid tumors. Cytometry 11:94-104, 1990 .

19. Shackney SE, Erickson BW, Skramstad KS: The T lymphocyte as a diploid reference standard for flow cytometry. Cancer Res 39:4418$4422,1979$.

20. Shankey TV, Rabinovitch PS, Bagwell B, Bauer KD, Duque RE, Hedley DW, Mayall BH, Wheeless L: Guidelines for implementation of clinical DNA cytometry. Cytometry 14:472-477, 1993.

21. Siegfried TM, Ellison DJ, Resau JH, Miura I, Testa JR: Correlation of modal chromosome number of cultured non-small cell lung carcinomas with DNA Index of solid tumor tissue. Cancer Res 51:3267$3273,1991$.

22. Smeets AWGB, Pauwels RPE, Beck JLM, Geraedts JPM, Debruyne FMJ, Laarakkers L, Feitz WFJ, Voous GP, Ramaekers FCS: Tissue specific markers in flow cytometry of urological cancers. III. Comparing chromosomal and flow cytometric DNA analysis of bladder tumors. Int J Cancer 39:304-310, 1987.

23. Susini T, Rapi S, Savino L, Boddi V, Berti P, Massi G: Prognostic value of flow cytometric deoxyribonucleic acid index in endometrial carcinoma: comparison with other clinical-pathologic parameters. Am J Obstet Gynecol 170:527-435, 1994.

24. Tribukait B, Granberg-Ohman I, Wijkstrom H: Flow cytometric DNA and cytogenetic studies in human tumors: $A$ comparison and discussion of the differences in modal values obtained by the two methods. Cytometry 7:194-199, 1986

25. Tribukait B, Gustafson H, Esposti P: Ploidy and proliferation in human bladder tumors as measured by flow cytometric DNA analysis and its relations to histopathology and cytology. Cancer 43:1782$1751,1979$.

26. Wolman SR, Camuto PM, Golimbu M, Schinella R: Cytogenetic, flow cytometric, and ultrastructural studies of twenty-nine non familial human renal carcinomas. Cancer Res 48:2890-2897, 1988. 